\title{
Micro-structural and Microhardness Study of Ni-Zn Ferrite Using Si Additive
}

\author{
Uzma $\mathbf{G}^{*}$ \\ Department of Physics, University of Wah, Wah Cantonment, Pakistan \\ Received 6 April 2013, accepted in final revised form 6 June 2013
}

\begin{abstract}
Mixed Ni-Zn ferrites $(x=0.66,0.77,0.88,0.99)$ were prepared by the double sintering ceramic method. Locally available low cost $\mathrm{Fe}_{2} \mathrm{O}_{3}$ with $0.5 \mathrm{wt} \%$ of Si additive was used for this purpose to reduce the process price markedly and to improve the properties of the ferrite produced. Micro structural and micro hardness properties along with density and porosity have been investigated. Hardness increases with increase in metal contact, $\mathrm{x}$ of $\mathrm{Ni}_{\mathrm{x}} \mathrm{Zn}_{1-\mathrm{x}} \mathrm{Fe}_{2} \mathrm{O}_{4}$. SEM and optical micrograph shows very similar morphology of the particles with the amount of $\mathrm{Si}(0.5 \mathrm{wt} \%)$, must be low enough to prevent growth of large grains.
\end{abstract}

Keywords: Ni-Zn Ferrites; Si additive; Micro-hardness, Micro-structural properties (C) 2013 JSR Publications. ISSN: 2070-0237 (Print); 2070-0245 (Online). All rights reserved. doi: http://dx.doi.org/10.3329/jsr.v5i3.14467 J. Sci. Res. 5 (3), 415-420 (2013)

\section{Introduction}

Nickel-zinc ferrites are ferromagnetic materials with a large number of technological applications in telecommunications and entertainment electronics. It is well known that $\mathrm{Ni}-\mathrm{Zn}$ ferrites are successfully used in high frequency range due to their high resistivity, mechanical hardness, high Curie temperature, low porosity and chemical stability [1,2]. These are extremely sensitive to the manufacturing process and hence, their properties are micro-structurally dependent $[3,4,5]$. Thus, to have a good understanding of the behavior of these materials, it is imperative to perform systematic investigations of their properties, in particular, the micro-structural and micro-hardness evolution. The present work is aimed to produce Ni-Zn ferrite using low cost iron oxide, having $0.5 \mathrm{wt} \%$ of Si additive to improve these properties of ferrite samples.

\section{Materials and Methods}

Ferrite samples with compositions $\mathrm{Ni}_{x} \mathrm{Zn}_{1-\mathrm{x}} \mathrm{Fe}_{2} \mathrm{O}_{4},(x=0.66,0.77,0.88$ and 0.99$)$ were prepared in polycrystalline form by high temperature solid-state reaction method. The

*Email: uzigh@yahoo.com 
diffraction patterns are taken after final sintering of $1473 \mathrm{~K}$ for $6 \mathrm{hrs}$ in a muffle furnace. The samples were quenched in air and X-ray diffraction (XRD) patterns were taken by using Rigaku XRD D/MAXIIA diffractometer using $\mathrm{CuK} \alpha$ radiation of $1.54^{\circ} \mathrm{A}$ with scanning speed of $1^{\circ}(2 \theta / \mathrm{min})$ to identify the phases formed and to confirm the completion of the chemical reaction [ 6]. JEOL 2000 CX Scanning Electron Microscope (SEM) and Nikon Optical Microscope were employed to examine the micro-structural features such as grain size and porosity. Micro-hardness tests of all the compositions of ferrite were performed on the same samples. A Leitz miniload 2 diamond pyramid microhardness tester was used for this purpose. A $200 \mathrm{~g}$ load was used to measure the hardness values presented in this paper.

\section{Results and Discussion}

\subsection{Micro structural study}

The microstructure and compositional analysis of all the ferrite samples were studied systematically by optical microscopy (OM), and scanning electron microscopy (SEM). The samples for optical and scanning electron microscopy were prepared by mounted the samples in cold setting resin making a size $30 \mathrm{~mm}$ in height and $30 \mathrm{~mm}$ in diameter suitable for loading into the electron microscope. The samples were then polished in four stages of $14,6,3$, and $1 \mu \mathrm{m}$ on a polishing wheel using diamond spray [7]. All the samples were etched firstly with $2 \%$ nital solution for few seconds to reveal the microstructure of the affected areas.

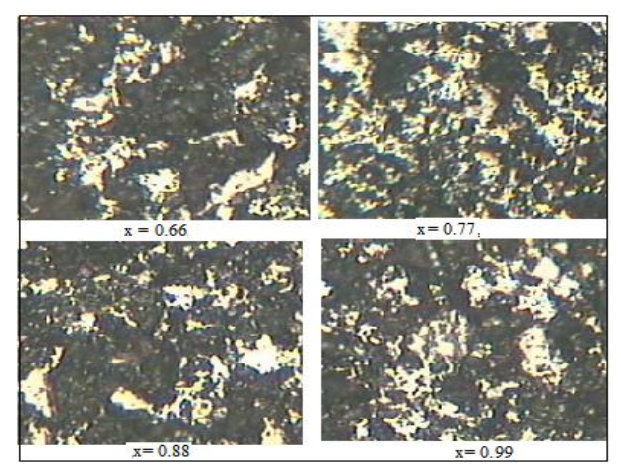

Fig. 1. Optical micrograph of Ni-Zn ferrite system for $x=0.66,0.77,0.88,0.99$ (X250).

\subsubsection{Optical microscopy}

Low magnification (X 250) optical micrographs were attained to determine the grain size and to observe the distribution of different phases formed. The results from optical 
micrograph show the distribution of phases, chemical homogeneities and porosity along with grains formation. All the samples of $\mathrm{Ni}_{\mathrm{x}} \mathrm{Zn}_{1-\mathrm{x}} \mathrm{Fe}_{2} \mathrm{O}_{4},(x=0.66,0.77,0.88$ and 0.99) are sound, homogeneous and free from any sort of macro porosity as shown in Fig. 1.

\subsubsection{Scanning electron microscopy}

The microstructure analysis of these samples was carried out using the high resolution Scanning electron microscope operated at $25 \mathrm{kV}$ in the Secondary electron image mode. It is useful to study the microstructure and to identify the phases farmed during sintering. It is also useful to interpret the amount of porosity and find out the size of grains and their positions in the crystal. The morphology of grain structure of $\mathrm{Ni}_{\mathrm{x}} \mathrm{Zn}_{1-\mathrm{x}} \mathrm{Fe}_{2} \mathrm{O}_{4}$ as seen from the scanning electron micrographs in Fig. 2, are maximum of cellular type particles with major phase of $\mathrm{Ni}-\mathrm{Zn}$ ferrite and minor phase of $\mathrm{Zn}_{2} \mathrm{SiO}_{4}$ (zinc silicate) due to its less

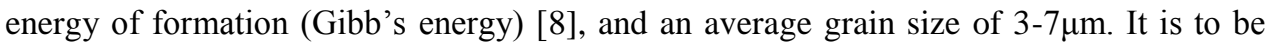
noted that the addition of $\mathrm{Si}$ suppressed the grain growth and causes the grain size to decrease. The small grains are preferred in ferrites as with decreasing grain size the values of micro-hardness were improved $[9,10,11]$. It is also interpret from the micrograph of this series of $\mathrm{Ni}-\mathrm{ZnFe}_{2} \mathrm{O}_{4}$ (Fig. 2), that second phase (zinc silicate) dominates more for $x=0.88$ and $x=0.99$. The decrease of porosity by increasing Ni concentration in this series of ferrite is again clear from both optical and scanning electron micrographs.

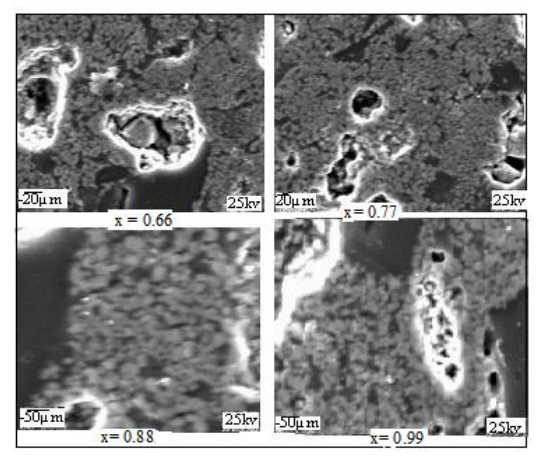

Fig. 2. SEM micrographs of Ni-Zn ferrite system for $x=0.66,0.77,0.88,0.99$.

\subsection{Micro-hardness study}

Micro-hardness tests of all the compositions of ferrite were performed on the same samples prepared for the optical microscopy. It was revealed that the hardness measured on all the samples of Ni-Zn ferrite compositions showed values, in the range of 765-860. At least three readings on each sample were taken to ensure the reproducibility. The diameter of the indentation produced on the sample was measured by applying a standard pressure for a standard length of time by means of a pyramid-shaped diamond. The 
diagonal of the resulting indention is measured under a microscope and the Vickers Hardness value read from a conversion table.

The hardness trends obtained are better than those reported in the literature for different compositions of Ni-Zn, ferrites [11, 12]. It has been observed that composition of $\mathrm{Ni}-\mathrm{Zn}$ ferrite with $\mathrm{Si}$ additive have higher values of hardness than as reported in the literature. This is because $\mathrm{NiO}$ form double bonding due to some ionic character with $\mathrm{O}_{2}$, which further increases its polarity and generate strong interaction among ions. Moreover, in all the above compositions we added $0.5 \mathrm{wt} \%$ of $\mathrm{Si}$, which reacts with $\mathrm{O}_{2}$ and forms tetrahedral oxide structure. These tetrahedral are resistant to applied forces and their electro negativity values are high which help to make the material harder.

The effect of $\mathrm{Si}$ addition on hardness of different compositions of ferrites has also been studied by other researchers [13-15] and observed that the micro-hardness was increased with $\mathrm{Si}$ addition.

\subsubsection{Effect of metal content on hardness}

Study also shows that the hardness value of a ferrite system depends on the metal content, $x$. The hardness value increases with increase in metal content, $x$ in Ni-Zn as shown in Fig.3. This was an expected usual trend of hardness corresponding to the hardness values of the alloying constituent $\mathrm{Ni}$, in the ferrite composition formed.

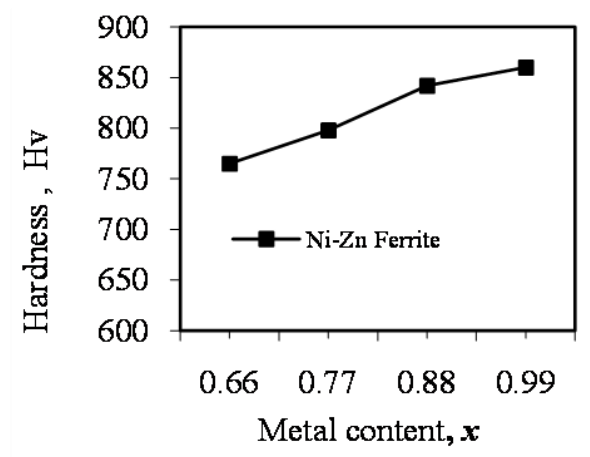

Fig. 3. Effect of metal content, $x$ on the hardness of Ni-Zn ferrites system.

\subsubsection{Effect of density and porosity on hardness}

The effect of density and porosity on hardness for different compositions of Ni-Zn ferrite is shown in Fig. 4 and Fig. 5 respectively. It has already been discussed [6] that bulk density increases by increasing the concentration of Ni ferrite systems. Increase in bulk density can be attributed to the difference in specific gravity of the ferrite components, as $\mathrm{NiO}\left(6.72 \mathrm{~g} / \mathrm{cm}^{3}\right)$ is heavier than $\mathrm{ZnO}\left(5.60 \mathrm{~g} / \mathrm{cm}^{3}\right)$, Some researcher [12-14] shows in 
their work that the hardness of ferrites exhibited a greater dependence on the grain size than on the density of the sample.

Porosity decreases and hardness increases in this case, as the number of pores is reduced by increasing $\mathrm{Ni}$ concentration, consequently, grains come closer to each other, the grain to grain contact area is increased leading to greater densification or less porosity.

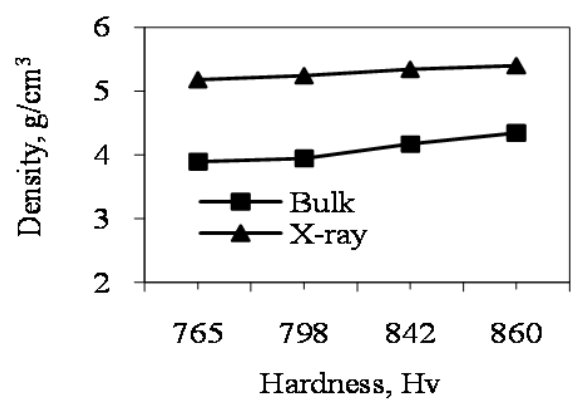

Fig. 4. The effect of hardness on density of the $\mathrm{Ni}_{\mathrm{x}} \mathrm{Zn}_{1-\mathrm{x}} \mathrm{Fe}_{2} \mathrm{O}_{4}$ ferrite system.

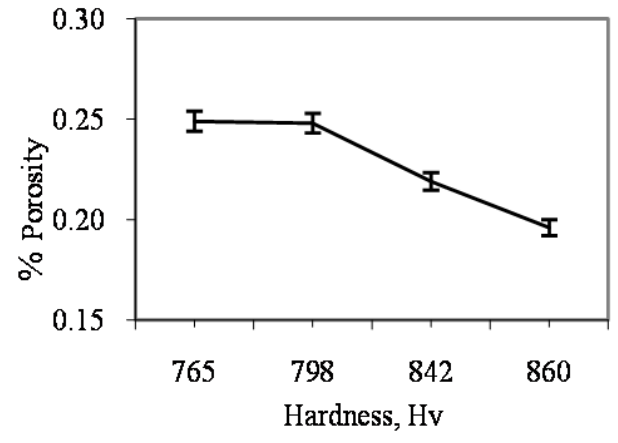

Fig. 5. The effect of \%Porosity on the $\mathrm{Ni}_{\mathrm{x}} \mathrm{Zn}_{1-\mathrm{x}} \mathrm{Fe}_{2} \mathrm{O}_{4}$ ferrite system.

\section{Conclusion}

Nickel Zinc ferrites with compositional formula, $\mathrm{Ni}_{\mathrm{x}} \mathrm{Zn}_{1-\mathrm{x}} \mathrm{Fe}_{2} \mathrm{O}_{4}$ were prepared by conventional double sintering method, using low cost $\mathrm{Fe}_{2} \mathrm{O}_{3}$ with $0.5 \mathrm{wt} \% \mathrm{Si}$ as an additive in order to improve the properties of the samples and controlled the process economics. The micro-structural and micro-hardness properties with other parameter such as density and porosity are reported. The microstructure of all the ferrite compositions produced was found homogenous through out the entire matrix region. The microscopy of the ferrite samples revealed fine cellular microstructures with an average grain size of 30 $\mu \mathrm{m}$.

The micro-hardness of all the samples was consistent from top to bottom of the ferrite matrix. The hardness values obtained were comparable with those reported in the literature and found better results due to presence of $\mathrm{Si}$ in the composition, which suppressed the ceramic grain growth and enhanced the micro-structural and hardness properties.

Microstructure and micro-hardness properties were correlated. Hardness value increases with increase in metal content, $\mathrm{x}$ in Ni-Zn. Porosity decreases and hardness increases in case of $\mathrm{Ni}-\mathrm{Zn}$ ferrite systems by increasing Ni concentration

\section{References}

1. T. Nakamura, J. Mag. Magn. Mater. 168, 285 (1997). http://dx.doi.org/10.1016/S0304-8853(96)00709-3 
2. G. P. Lopez, S. P. Silvetti, S. E. Urreta, A. C. Carreras, J. Alloys Comp. 505, 808 (2010).

3. A. C. F. M. Costa, E. Tortella, M. R. Morelli, R. H. G. A. Kiminami, J. Mag. Magn. Mater. 256 174 (2003). http://dx.doi.org/10.1016/S0304-8853(02)00449-3

4. Z. Zheng, H. Zhang, J.Q. Xiao, Q. Yang, L. Wang, and H. Su, J. Appl. Phys. 111, 07A336 (2012).

5. T. Jahanbin and M. Hashim, Solid State Sci. Tech. 17, 243 (2009).

6. G. Uzma, Pak. J. Sci. Ind. Res. 53, 104 (2010).

7. G. Abbas, Ph.D.Thesis, University of London (1990).

8. J. S. Collin, Metals Reference Book (Academic Press, London, 1968).

9. A. Barba, C. Clausell, J. C. Jarque, and M. Monzó, J. Europ. Cera. Soc. 31, 2119 (2011). http://dx.doi.org/10.1016/j.jeurceramsoc.2011.05.007

10. X. Fan, H. Ren, Y. Zhang, S. Guo, and X. Wang, Rare Metals 27, 287 (2008). http://dx.doi.org/10.1016/S1001-0521(08)60131-X

11. W. D. Kehr, C. B. Meldrum, and R. F. M. Thomley, Wear 31, 109 (1975). http://dx.doi.org/10.1016/0043-1648(75)90125-8

12. A. Dias and R. L. Moreira, Mater. Lett. 939, 69 (1999). http://dx.doi.org/10.1016/S0167-577X(98)00219-5

13. L. Holappa, V. Ollilainen, and W. Kasprzak, J. Mater. Process. Tech. 109, 78 (2001). http://dx.doi.org/10.1016/S0924-0136(00)00778-0

14. In-Wook Park, S. R. Choi, Mi-Hye Lee, and K. H. Kim, J. Vac. Sci. Technol. A 21, 895 (2003).

15. K. Wang, Y. Sun, Y. Li, X. He, J. Alloys and Comp. 494, 236 (2010). 